\title{
Ganglion of the hip joint - We present a logical approach to the exploration of a mass in the femoral triangle
}

\author{
Surg Lt MD Clarke \\ BSc,MBBS,RN \\ SHO Surgery
}

\author{
Maj DP Edwards \\ FRCSE,RAMC \\ Specialist Registrar
}

\section{Surg Cdr P Barker \\ MS,FRCS,FICS,RN \\ Consultant Surgeon}

Department of Surgery, Royal Hospital Haslar, Gosport, Hants PO12 2AA

SUMMARY: Hip joint ganglion is a rare cause of a mass in the femoral triangle. Our patient presented with a swelling in the groin and a history of femoral hernia repair 5 years previously. Pre-operative assessment with ultrasound suggested a possible femoral artery aneurysm. We propose that safe exploration of a mass closely related to the femoral vessels must include vascular control.

\section{Introduction}

Ganglia are cystic lesions of uncertain aetiology usually attached to the joint capsule or tendon sheath. They spread along anatomical planes and are most commonly associated with joints of the wrist and knee. We found eighteen cases of cysts communicating with the hip, presenting as a mass in the femoral triangle, reported between 1952 and 1997. The rarity of hip ganglia means that they are not usually considered in the differential diagnosis of groin swellings. A clinician should always prepare for the unexpected, and the surgical approach should be planned to allow for all eventualities.

\section{Case Report}

A 97 year old lady presented with a twelve month history of an enlarging irreducible lump in her left groin causing intermittent but localised pain. Symptoms were alleviated when lying flat. Five years previously she had had an incarcerated left femoral hernia repaired. She gave no history of rheumatoid arthritis or hip disease.

On examination the swelling in the left femoral triangle lay over the femoral pulse and to its lateral side. There was a transmitted arterial pulsation but no cough impulse. Ultrasound demonstrated a $2-3 \mathrm{~cm}$ fluid filled cystic mass intimately related to the lateral wall of the common femoral artery but without evidence of pulsatile flow. These findings were suggestive of a false aneurysm. We suspected that the common femoral artery might have been damaged during her femoral hernia repair.

Exploration of the femoral triangle was performed under general anaesthetic through an inverted 'hockey-stick' incision; the short arm of this allowed extra-peritoneal exposure of the iliac vessels via a muscle splitting approach. The external iliac artery, superficial femoral artery and profunda femoris artery were looped with vascular slings to allow proximal and distal control of the possible aneurysm. Dissection of the swelling revealed a $5 \mathrm{~cm}$ by $3 \mathrm{~cm}$ cystic mass lateral to and overlying a normal common femoral artery, and medial to (and displacing laterally) the femoral nerve (Fig 1). Viscous clear fluid was aspirated from the cyst, suggesting a diagnosis of either a ganglion of the hip joint or an iliopsoas bursa. Following the opinion of a consultant orthopaedic surgeon, further exploration revealed the 'cyst' was in communication with the hip joint. The mass was excised and the wound closed without closure of the joint capsule. The patient made an uneventful recovery and was discharged on the fifth postoperative day.

Histological examination of the cyst wall reported a thick degenerative lining without epithelium consistent with the diagnosis of ganglion arising from the hip joint.

\section{Discussion}

Ganglia are locular cystic cavities with a myxoid matrix. They often communicate with a joint space; they may have a lining of epithelium making them true synovial cysts. Their aetiology is uncertain however, and cystic degeneration of a joint capsule is a widely quoted popular hypothesis made by Ledderhouse in $1893(1,4)$.

Other suggestions include cystic swelling of tendon sheaths or bursae, embryological displacement of synovium, high intra-lumenal pressure causing herniation of synovial membrane through the joint capsule and attrition of the joint capsule by overlying tendon with subsequent expansion of the tendon sheath $(1,5,6)$.

Enlargement of a synovial bursa is often overlooked as a possible cause of a mass in the femoral triangle. Necropsy studies demonstrate the iliopsoas bursa is present in almost all adults and communicates with the hip joint in $14 \%$ of normal and up to $40 \%$ of arthritic hips (7). Its close association with the lateral boarder of the femoral artery is well described $(2,8)$.

Ganglia of the hip are a rare cause for a mass in the femoral triangle. Our search of literature found 18 cases of hip ganglia presenting with a mass in the femoral triangle reported in English language journals with other reports of enlarged noncommunicating iliopsoas bursae and ganglia presenting with symptoms of vascular occlusion but no palpable mass (1-9). Accurate preoperative diagnosis was made in four cases and on each occasion influenced the surgical procedure $(2,7,8)$. In 

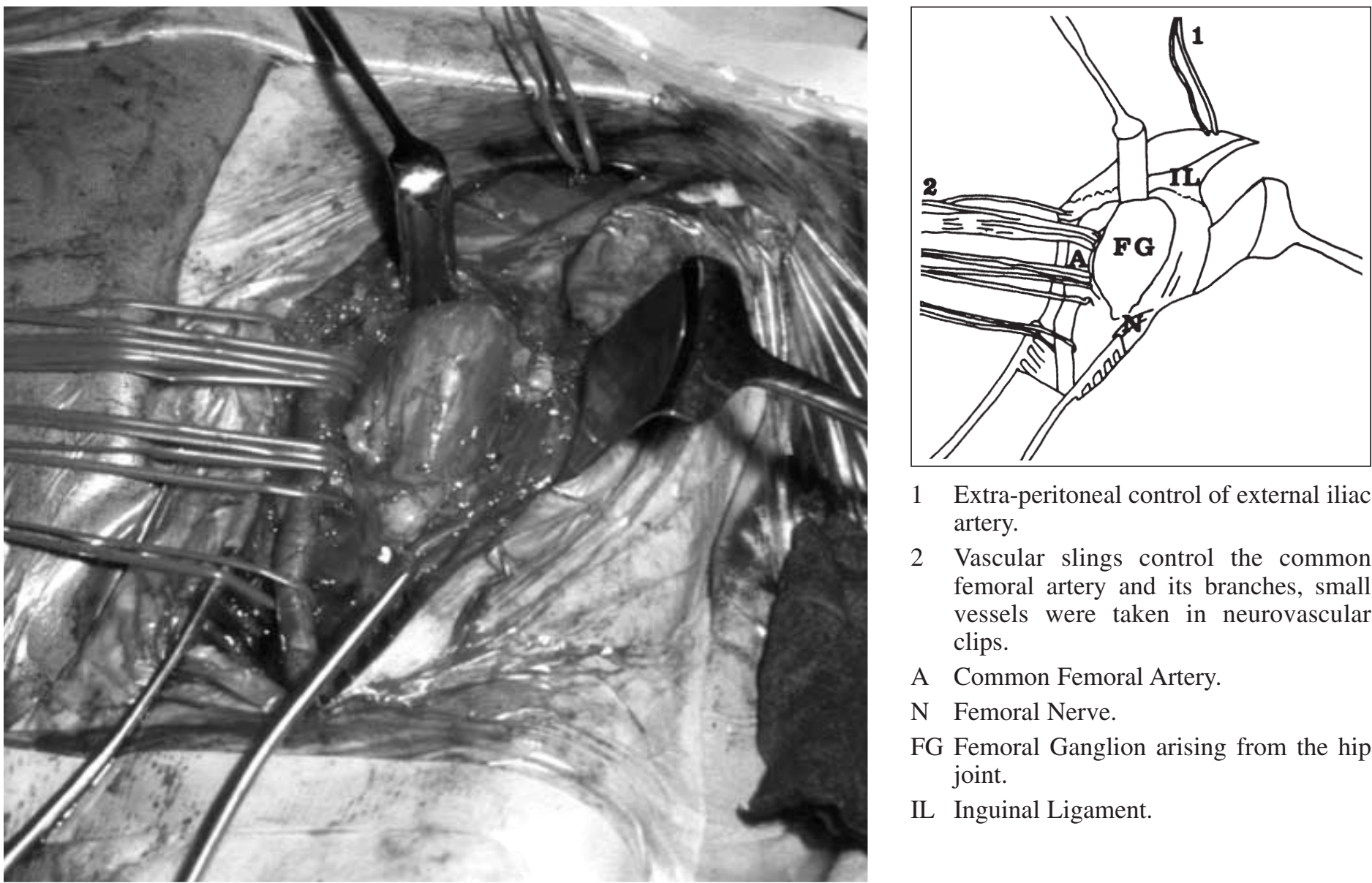

1 Extra-peritoneal control of external iliac artery.

2 Vascular slings control the common femoral artery and its branches, small vessels were taken in neurovascular clips.

A Common Femoral Artery.

N Femoral Nerve.

FG Femoral Ganglion arising from the hip joint.

IL Inguinal Ligament.

Fig 1. The Left femoral triangle - Access through the inverted hockey-stick incision.

all the others the correct diagnosis of hip ganglion was only made at operation. Several authors include aneurysm associated with the femoral artery in the differential diagnosis at the time of operation, others make reference to intimate association with the femoral vessels $(2-4,6)$.

Symptomatic hip disease is described in the majority of case reports although this was not a finding in our patient $(1,2,5,7,8)$. Vascular symptoms, predominantly venous compression have also been reported $(8,9)$. Operative findings often demonstrated a mass in close relation to the femoral artery displacing the artery medially and the femoral nerve laterally $(2,6)$.

Radiological imaging was often requested prior to surgery. The presence of intra-ganglionic gas, has been described as a rare but specific feature of hip joint ganglia (10). This feature, if present, may help differentiate between ganglia and false aneurysms, in the absence of a gas forming organism. The role of different imaging modalities in the investigation of femoral ganglia has been extensively discussed (5). Contrast CT would appear to be most informative.

Standard approaches to a femoral hernia do not afford good access to iliac vessels and approaches to a femoral aneurysm may hinder hernia repair. The inverted hockey stick allows extra-peritoneal control of the external iliac artery and superb exposure of all contents of the femoral triangle. We suggest that the high rate for mis-diagnosis of a femoral ganglion is of secondary importance, but mis-diagnosis of a false aneurysm could be catastrophic particularly when surgical exposure is poor.

\section{REFERENCES}

1. Golledge J, FABeR RG. Hip ganglion: case report and review of the literature. JR Coll Surg Edinb 1996; 41: 405407

2. White TK, Incavo SJ, Moreland MS. Giant synovial cyst of the hip joint. Orthop Review 1988; 17: 609-612.

3. HERRINGTON JL JR., Edwards LW. Ganglion cyst arising in unusual locations. Ann Surg 1955; 142: 900-903.

4. MCCREDIE JA. Ganglia presenting as an irreducible femoral hernia. J R Coll Surg Edinb 1979; 24: 231-233.

5. Sartorius DJ, Danzig L, Gilula L, Greenway G, RESNICK D. Synovial cysts of the hip joint and iliopsoas bursitis: A spectrum of imaging abnormalities. Skeletal Radiol 1985; 14: 85-94.

6. JAFFEY DC, NADE S. Painless groin swelling associated with osteoarthritis of the hip. JR Coll Surg Edinb 1986; 31: 185-186.

7. Forster BB, Connell DG, Scudamore CH. Synovial cyst of the hip: an unusual cause of an inguinal mass. Can J Surg 1989; 32: 133-134.

8. Bystrom S, Adalberth A, Milbrink J. Giant synovail cyst of the hip: an unusual presentation with compression of the femoral vessels. Can J Surg 1995; 38: 368-370.

9. Gale SS, Fine M, Dorsick SM, Whalen RC. Deep vein obstruction and leg swelling caused by femoral ganglion. $J$ Vasc Surg 1990; 12: 594-595.

10. Silver DAT, Cassar-Pullicino VN, Morrissey BM, ETHERINGTON RJ, MCCALL IW. Gas containing ganglia of the hip. Clin Radiol 1992; 46: 257-260. 